\title{
CORRELAÇÃO ESTRATIGRÁFICA DE POÇOS PARA CAPTAÇÃO DE ÁGUA SUBTERRÂNEA NA REGIÃO CAPIVARIIRAFARD, SP: DESCRIÇÕES LITOLÓGICAS MACROSCÓPICAS, MICROSCÓPICAS E PERFIS GEOFÍSICOS
}

\author{
SETEMBRINO PETRI*, CARLOS ALBERTO MENDONÇA**, MAURÍCIODE SOUZA BOLOGNA**, \\ JOSÉ MOACYR VIANNA COUTINHO***, PERCY CORREA VIEIRA**** \& \\ PEDRO FERNANDES BOTELHO*****
}

\begin{abstract}
STRATIGRAPHIC CORRELATION OF GROUNDWATER WELLS IN THE CAPIVARI/ RAFARD REGION, SÃO PAULO: MACROSCOPIC AND MICROSCOPIC LITHOLOGIC DESCRIPTIONS AND GEOPHYSICAL PROFILES- The approaches of this paper are twofpld. A - The lithological correlation of three wells drilled in the Capivari - Rafard region, State of São Paulo, Brazil, is proposed on the basis of macro and microscópio descriptions of sample lithologies from cores of the wells and geophysical logs (gamma rays and normal resisti vity). The proposed correlation is based on the deduced energy levels of the environment during sedimentation as inferred from grain size, sorting and sedimentary structures. B - The second apprpach is to confront the geophysical logs with the lithologic descriptions. The responses of geophysical logs to the lithologies are influenced by some lithological properties that are not always self-evident, such as, for instance, argillaceous content in sandstones, lithologic heterogeneities (e. g., as in diamictites), presence or absence of radioactive minerais. Four intervals of the sedimentary columns of the wells, with boundaries based on changes in the deduced energy of the environment of deposition, are proposed. Two of them, intervals B and D, are considered as aquifers.
\end{abstract}

Keywords: Permian, Itararé Subgroup, Paraná Basin, Brazil

RESUMO Este trabalho teve como um dos objetivos, a proposição de correlação de três poços perfurados na região Capivari - Rafard, SP, utilizando-se dos seguintes parâmetros: A - Litológicos : descrições macro e microscópicas de amostras dos testemunhos dos pocos e B - Perfilagens geofisicas. As correlações propostas se basearam nas deduções das condições de energia que presidiram a deposição dos sedimentos, com base na granulometria, grau de seleção e estruturas sedimentares.

Outro objetivo foi confrontar a perfilagem geofísica (raios gama e resistividade) com as descrições litológicas. As respostas das perfilagens geofisicas às iitologias, dependem de características nem sempre prontamente perceptíveis, como, por exemplo, quantidade de matriz argilosa nos sedimentos arenosos, heterogeneidade litológica, como é o caso dos diamictitos, presença ou ausência de minerais radioativos. Reconheceram-se quatro pacotes, delimitados por alternância das características dos sedimentos, sugestivas de condições de deposição de baixas e altas energias. Os sedimentos depositados em condições de alta energia constituem aquíferos, selados pelos sedimentos depositados em condições de baixa energia.

INTRODUÇÃO Os poços para captação de água subterrânea perfurados pelo Instituto Geológico da Secretaria de Estado do Meio Ambiente (IG-SMA), por terem testemunhagem completa, constituem um material importante para os estudos em subsuperficie, especialmente do Subgrupo Itararé, na região de Capivari-Rafard, no Estado de São Paulo.onde se con-centra a maioria das perfurações recentes. Particularmente neste trabalho, os testemunhos de três novos poços foram utilizados para efetuar a descrição litológica das formações perfuradas, confrontando com os perfis geofisicos de raios gama e de resistividade normal longa. Procurou-se com a análise dos testemunhos e suas comparacões com os perfis geofisicos, identificar as respostas dos perfis geofísicos às variações litológicas e assim delinear técnicas de interpretação em poços sem testemunhagem, que são em maior número na região.

Dos três poços estudados, o 22 situa-se em Capivari enquanto que o 26 e o 29 , situam-se em Rafard. Todos foram perfilados e tiveram seus testemunhos descritos em detalhe. Já o estudo em seção delgada foi efetuado apenas nos poços 22 e 26.0 poço 22, por ser representativo do Subgrupo Itararé em Capivari, foi particularmente importante para efetuar-se comparação com esta unidade em Rafard. Este trabalho divulga os dados obtidos e os interpreta frente aos anteriormente divulgados, especialmente os referentes aos poços Capim Fino (Maniakas 1986) e 3 (Petri 1992) ambos em Rafard, e o poçp 13 (Petri \& Pires 1992) em Capivari.
GEOLOGIA REGIONAL De acordo com o modelo de sedimentação admitido para a região (Pires \& Petri 1991, Petri \& Pires 1992, Petri 1992), os sedimentos foram depositados por fluxos submarinos de detritos provenientes de um continente emerso situado a nordeste da área estudada, além da atual Rodovia do Açúcar que liga Capivari a Piracicaba. Os fluxos se amalgamaram rampa abaixo fazendo com que os níveis de energia do meio aquoso se estabelecessem contemporaneamente em todo o declive, sendo gradativamente menos energéticos rumo a regiões mais profundas. De acordo com este modelo, os mergulhos iniciais dos sedimentos seriam para sudoeste, levantando a hipótese de que os mergulhos regionais atuais, que são para noroeste, sejam tectônicos.

Considerando estes mergulhos regionais, os poços 22,3 e 26 alinham-se segundo a direção das camadas (strike), e 0 poço 29 fica ligeiramente deslocado para oeste (Fig.l).

As Iitologias presentes podem ser correlacionadas considerando apenas o seu posicionamento admitindo a inexistência de falhas apreciáveis. Há de se considerar possíveis variações de espessura relacionadas a irregularidades no paleorelevo, a taxas de sedimentação e de compactação diferencial dos sedimentos.

\section{CARACTERÍSTICAS DOS POÇOS ANALISADOS}

Os poços estudados foram perfurados visando o abastecimento público de água. O poço 26 localiza-se no município de Rafard (coordenadas UTM de 239,8; 7449,05 km), cota da boca do poço de $540 \mathrm{~m}$ e profundidade de $300 \mathrm{~m}$. O diâmetro

\footnotetext{
* Instituto de Geociências - USP - Rua do Lago, 562 - CEP 05508-900 - Cidade Universitária - São Paulo-SP

** Instituto Astronómico e Geofísico - USP - Rua do Matão, 1226 - CEP 01065-970 - Cidade Universitária - São Paulo-SP

*** Instituto de Pesquisas Tecnolígicas - Av. Almeida Prado, 535 - CEP 05508-901 - Cidade Universitária - São Paulo-SP

**** Instituto Geológico - Secretaria do Meio AmbienteSão Paulo - Av. Miguel Stéfano 3900 - CEP 04301-903 São Paulo-SP (Água Funda)
} 
Tabela l- Posição das seções delgadas

Table 1 - Location of thin sections

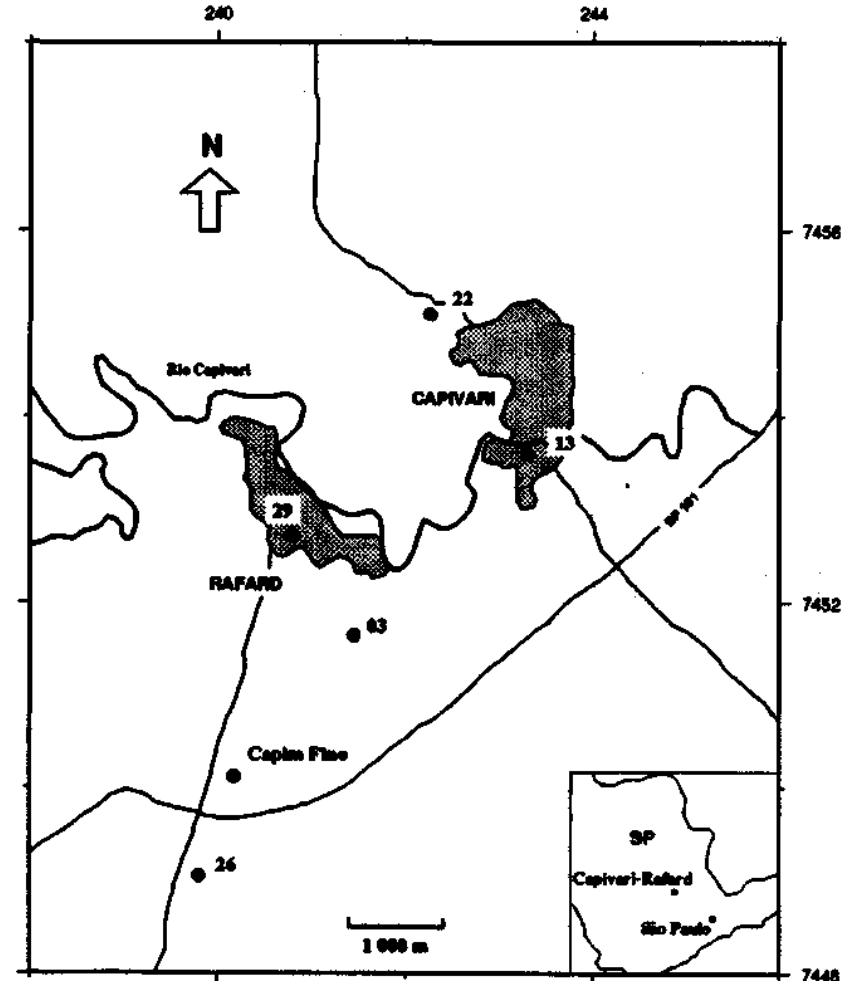

Figura 1 - Localização dos poços - Coordenadas UTM Figure l - Location map - UTM Coordinates

varia com a profundidade sendo 14 " nos primeiros $24 \mathrm{~m}, 10$ " de 24 a 102 m, 8" de 102 a $203 \mathrm{~m}$ e 6" de 203 a $300 \mathrm{~m}$.

O poço 29 localiza-se no município de Rafard (coordenadas: 240,$8 ; 7427 \mathrm{~km}$ ), na cota de $540 \mathrm{~m}$ e profundidade de $283 \mathrm{~m}$. Seu diâmetro é de 14 " de 0 a $30 \mathrm{~m}, 10^{\prime \prime}$ de 30 a 100 m, 8" de 100 a 187 m, 6" de 187 a 221 m e 5" de 221 a $283 \mathrm{~m}$.

O poço 22 localiza-se no município de Capivari (coordenadas: 242,$25 ; 7455,1 \mathrm{~km}$ ), na cota de $505 \mathrm{~m}$ e profundidade de $300 \mathrm{~m}$. Seu diâmetro é de $14 "$ até $29,5 \mathrm{~m}, 10$ " de 29,5 a $100,6 \mathrm{~m}, 8^{\prime \prime}$ de 100,6 a 180,6 m e 6" de 180,6 a $300 \mathrm{~m}$.

Todos os poços foram revestidos por tubos de aço nos primeiros $30 \mathrm{~m}$ para evitar a contaminação das aguas subterrâneas.

METODOLOGIA As correlações dos poços foram baseadas nas condições de energia dos ambientes aquosos que presidiram a sedimentação. Os níveis de energia foram classificados em alto, moderado ou baixo, tendo como base 0 estudo das litologias e estruturas reconhecidas nos testemunhos em escalas macroscópica e microscópica. Os perfis geofísicos contribuíram para delimitar os pacotes litológicos principalmente quando foi possível reconhecer em litologias distintas, padrões sugestivos de variações faciológicas similares. As amostras para a confecção de seções delgadas foram coletadas em horizontes pré-determinados visando auxiliar a descrição macroscópica ou verificar hipóteses levantadas pela análise dos perfis.

A apresentação e discussão dos resultados é realizada segundo intervalos descritos a partir do fundo de cada poço. Para cada intervalo faz-se um resumo das litologias e estruturas reconhecidas no testemunho, em seguida, efetua-se a interpretação dos perfis geofísicos, finalizando com a apresentação dos resultados obtidos em seções delgadas, cujas localizações constam da Tabela 1.

\begin{tabular}{|c|c|c|}
\hline Seçio delgada & Profundidade (m) & Poço \\
\hline Thin section & Depth (m) & Well \\
\hline 1 & 272 & 26 \\
\hline 2 & 276 & 26 \\
\hline 3 & 264 & 26 \\
\hline 4 & 205 & 26 \\
\hline 5 & 185 & 26 \\
\hline 6 & 175 & 26 \\
\hline 7 & 166 & 26 \\
\hline 8 & 164,5 & 26 \\
\hline 9 & 150 & 26 \\
\hline 10 & 138 & 26 \\
\hline 11 & 104 & 26 \\
\hline 12 & 80 & 26 \\
\hline 13 & 30 & 26 \\
\hline 14 & 300 & 22 \\
\hline 15 & 277 & 22 \\
\hline 16 & 269,7 & 22 \\
\hline 17 & 222 & 22 \\
\hline 18 & 196 & 22 \\
\hline 19 & 138,5 & 22 \\
\hline 20 & 119 & 22 \\
\hline 21 & 76 & 22 \\
\hline 22 & 46 & 22 \\
\hline 23 & 34 & 22 \\
\hline
\end{tabular}

PERFIS GEOFÍSICOS A perfilagem dos poços foi realizada com um perfilador portátil, modelo Geologger 3030 , fabricado pela OYO Corporation, do Japão. A contagem da emissão de raios gama é feita por um cintilômetro de iodeto de sódio ativado com tálio, com 1/2" de espessura e 2 " de comprimento, localizado no centro da sonda. As leituras de resistividade elétrica foram obtidas no arranjo normal longo (Telford et al., 1976). A perfilagem em cada poço estendeu-se até $284 \mathrm{~m}$ devido ao comprimento do cabo do perfilador. As medidas foram tomadas a cada 20 centím tanto na descida quanto na subida da sonda, desconsiderando na interpretação os intervalos em que as leituras não se repetiram. Acima do nível estático, não se efetuam medidas de resistividade elétrica, pois os eletrodos não ficam conectados à formação.

Os perfis foram interpretados qualitativamente, procurando reconhecer nos mesmos as variações litológicas identificadas nos testemunhos. Como comenta Rider (1990), variações na composição e estrutura das rochas podem imprimir efeitos similares nos perfis dificultando sua interpretação. Neste contexto, a análise frente aos testemunhos tornase oportuna no sentido de delinear critérios para interpretar perfis em poços sem testemunhagem.

Neste trabalho, tanto o perfil de raios gama quanto o de resistividade normal foram utilizados para inferir variações litológicas em profundidade. O emprego do perfil de resistividade elétrica para esta finalidade mostrou-se viável pois a resistividade da água nos poços perfilados é bastante alta (1600 ohm.m no poço 29, por exemplo) tornando a resistividade dependente apenas da porosidade e da composição mineralógica da rocha e não da quantidade de sais em solução.

Nos horizontes em que a variação faciológica é associada ao conteúdo em argila, verificou-se que o perfil de resistividade apresenta correlação negativa com o de raios gama. Por isto, mostrou-se conveniente adotar a hipótese que a existência de correlação negativa entre os dois perfis indica variação 
litológica condicionada pelo conteúdo em argila. Caso contrário, passa-se a suspeitar que as variações litológicas são condicionadas pela variação de porosidade ou da composição mineraló gica do arcabouço ou da matriz. $O$ estudo posterior dos testemunhos verificou a validade destas hipóteses que, certamente, poderão ser empregadas na interpretação e correlação nos poços da região ou em terrenos com geologia semelhante.

POÇO 26 Neste poço foram reconhecidos cinco intervalos de sedimentos que são mostrados na figura 2 juntamente com a seção litológica, os perfis geofísicos e as posições de coleta de amostras para seções delgadas.

INTERVALO I (300 A $258 \mathrm{M})$ Inicia-se com lamito, de 300 a 298,3 m, maciço, de cor cinza, contendo pequenos seixos de litologias variadas e intraclastos de argilito cinza escuro com cimento carbonático. Os siltitos ocorrem até a profundidade de $264 \mathrm{~m}$.

No perfil de raios gama, este intervalo caracteriza-se por contagens altas, frequentemente maiores que $25 \mathrm{cps}$. O aumento de emissão entre 272 e $277,5 \mathrm{~m}$ foi interpretado como devido a um aumento de elementos radioativos que normalmente concentram-se nos níveis com maior quantidade de matéria orgânica. $\mathrm{O}$ estudo da seção delgada 01 reconhece faixas de siltitos, grosso e fino, e bandas argilosas mais escuras do argilomineral illita impregnado de material pardo, possivelmente matéria orgânica. $O$ perfil de resistividade acusa 0 decréscimo da resistividade rumo ao topo do intervalo sugerindo diminuição no conteúdo em matéria orgânica. Deve-se considerar que medições de resistividade elétrica em folhelhos da Formação Irati mostraram que os níveis enriquecidos em matéria orgânica são mais resisti vos (Paula Neto, 1988).

A seção delgada 01 mostra que as faixas siltíticas são salpicadas por calcita ( $1 \%$ em volume) e de material opaco $(5 \%)$, certamente impregnados com matéria orgânica. Há concentração de minerais pesados transparentes, especialmente rutilo, turmalina e zircão. Verificam-se laminações irregulares, sugestivas de zonas de turbulência, à semelhança do que se observa macroscopicamente nos testemunhos, particularmente nos níveis mais argilosos. Originalmente, estes sedimentos seriam plásticos e favoreceriam a ocorrência de deslizes sindeposicionais.

Outra observação interessante deste intervalo, é a relacionada à seção delgada 02 . Trata-se de um siltito fino a grosso, intercalado com arenito muito fino. Chama a atenção a presença de calcita em grãos isolados, possivelmente de origem elástica. Ocorrem também, manchas poiquilotópicas de calcita. Minerais pesados, tais como rutilo, estaurolita, apatita, granada e outros se concentram em certos níveis. A seção delgada 03 constitui-se de siltito fino a médio, homogéneo (0,010 a 0,020 microns) com cimento em manchas carbonáticas. Os grãos são constituídos de quartzo (60 a 70\%), carbonatos de cálcio elásticos $(20 \%)$, feldspatos (10 a 20\%) e micas $(5 \%)$.

Os sedimentos que constituem este intervalo, seriam o resultado de uma fase de baixa energia do corpo líquido, com condições favoráveis à conservação de matéria orgânica, representando um ciclo sedimentar parcialmente revelado pela sondagem. O limite deste intervalo com o superior é constituído de brecha sedimentar, descrita no intervalo seguinte.

INTERVALO II (258-254 M) A brecha deste intervalo é constituída de fragmentos decimétricos de arenito muito fino, imersos em matriz de arenito grosso, o que evidencia sua origem sedimentar. Ela representa uma fase de aumento de energia da água, que teria remobilizado parte do arenito muito fino do topo do intervalo inferior redepositando-o, após pequeno transporte e seleção que propiciou a deposição do arenito grosso da matriz.
INTERVALO III (254-151 M) É constituído por dois pacotes de arenitos. O sub-intervalo IIIa, de 254 a $215 \mathrm{~m}$ caracteriza-se por arenitos médios a finos, com intercalações subordinadas de filmes argilosos. Principalmente na parte inferior deste intervalo, os perfis de raios gama e de resistividade possuem correlação negativa, indicando que a variação de facies sedimentar deve estar condicionada pelo conteúdo em argila. A forma em funil na curva de raios gama, entre 241 e $229 \mathrm{~m}$, indica granocrescência ascendente que é reconhecida nos testemunhos; a 238,3 m, por exemplo, ocorre uma camada de lamito com clastos que grada para arenitos com granulações fina e média no topo. Os incrementos na emissão gama em 241 e $251 \mathrm{~m}$, associam-se a sedimentos com maior quantidade de matriz caulínica.

A presença de litologias mais arenosas, com estruturas de granocrescência ascendente, sugere a retomada de condições mais enérgicas no regime de fluxo, embora não tão intensas quanto as estabelecidas no intervalo $\mathrm{H}$.

O subintervalo IIIb, de 215 a $151 \mathrm{~m}$ apresenta valores de raios gama, em geral, mais elevados e variáveis que os do intervalo sotoposto, embora a resistividade elétrica permaneça no patamar de $180 \mathrm{ohm} . \mathrm{m}$. Isto sugere que a variação de facies sedimentar não deve ser condicionada pela porosidade ou pelo conteúdo em argila, já que tais param também afetariam a resistividade elétrica. E de se esperar, então, que a variação de facies, indicada pelo perfil gama, seja reflexo dos minerais que constituem o arcabouço das rochas. Devido à existência de feldspatos potássicos no arcabouço, levantou-se a hipótese de que a quantidade deste mineral estaria condicionando a emissão de raios gama já que o isó topo ${ }^{40} \mathrm{~K}$ é radioativo.

Para verificar tal hipótese confeccionaram -se as seções delgadas 4,5,6,7 e 8, as quais, embora situadas em horizontes com diferentes valores de emissão gama, revelaram a mesma quantidade de feldspatos potássicos, na ordem de $15 \%$. Uma explicação plausível para esta aparente contradição, pode residir na diferente escala de informação fornecida por cada um dos métodos: o perfil geofísico expressando um volume na ordem de decím cúbico de rocha na vizinhança do ponto de medida e a secção delgada uma área de apenas alguns centím quadrados. A diferença na escala de investigação pode fornecer resultados contraditórios, principalmente em formações heterogéneas, depositadas em ambientes de alta energia como é o caso dos arenitos arcoseanos em questão. Entretanto, não se pode descartar a hipótese de que os elementos radioativos estejam contidos em outra fração mineralógica 0 que poderia ser esclarecido com o estudo dos testemunhos existentes.

A descrição mais detalhada das informações em seção delgada é dada a seguir. A seção delgada 05 exibe intercalações irregulares de silte médio, às vezes com grãos de areia fina, lentes e faixas irregulares e pouco selecionadas de silte grosso, areia muito fina, fina e média, com o predomínio de areia fina. Os grãos de areia média são subangulosos e arredondados e com feldspatos potássicos totalizando cerca de $15 \%$ do volume.

A seção delgada 06 pode ser dividida em duas porções: uma constituída de areia fina a média, com pouca seleção, e a outra, silte fino a médio com linhas argilosas e algumas lentes ou grãos isolados de areia fina. A areia média tem cerca de $80 \%$ de quartzo, $5 \%$ de plagioclásios e $15 \%$ de microclínio. Estaurolita, zircão, turmalina e minerais opacos formam os minerais pesados. A secção 07 constitui-se de silte fino a médio, com mica isorientada como em folhelho. A seção delgada 08 mostra-se corno arenito médio, com boa seleção e bom arredondamento. Quartzo constitui $70 \%$ dos grãos $(5 \%$ de plagioclásios, $15 \%$ de microclínio). $\mathrm{O}$ cimento é constituído de sericita (muscovita fina de $2 \%$ ) e carbonato de cálcio $(3 \%)$.. 


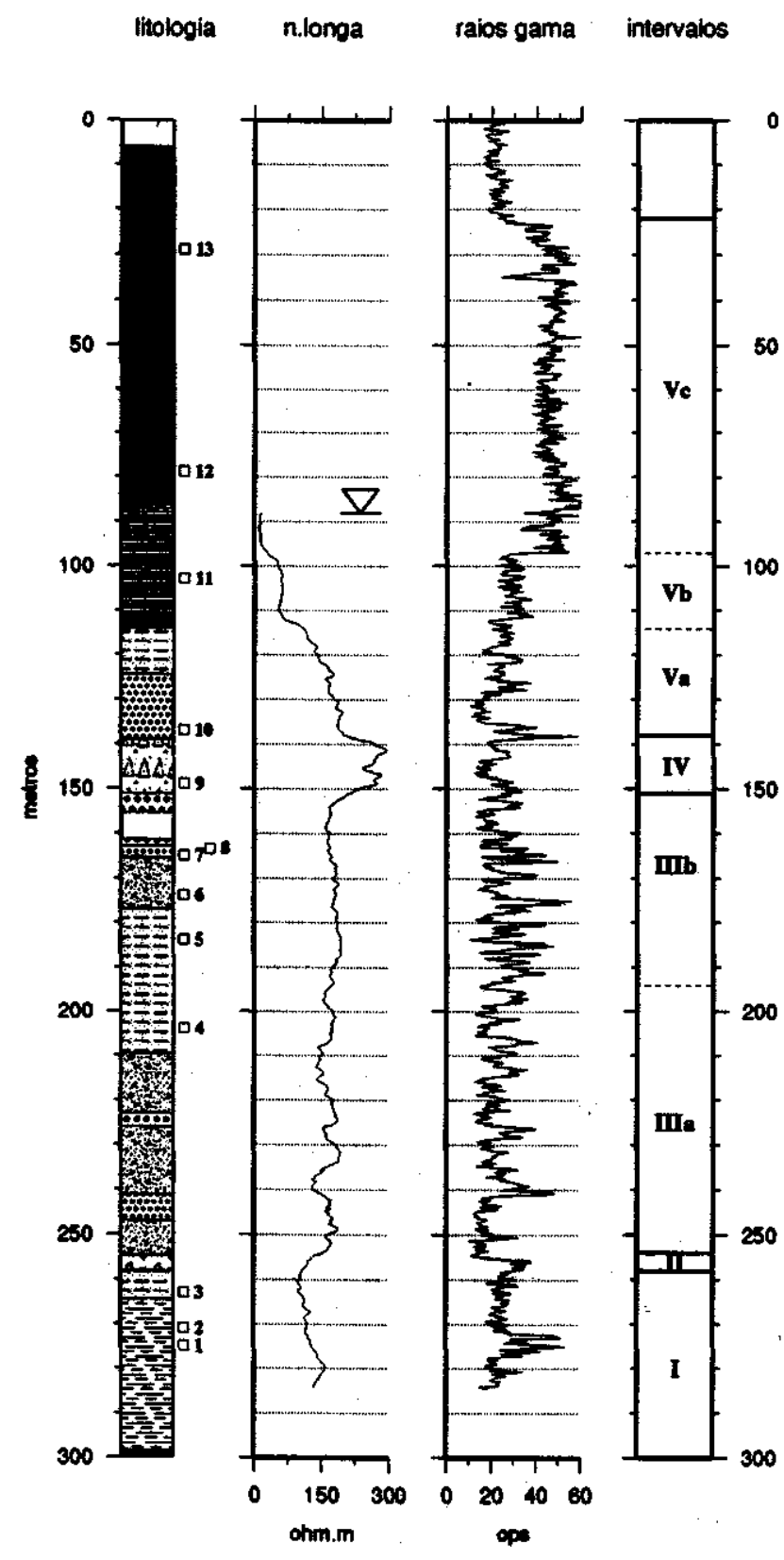

lamito

ritmito

arenito muito fino

arenito fino a muito fino

arenito fino

testemunlios inerrecuperados

conglomerado c/ matrix arenosa

arenilo médio

diamictito de matriz lamitica

arenito grosso a médio

arenito grosso

brecha de matriz arenosa

siltito

$\Delta 4$ diamctito de matriz arenosa

Figura 2 - Poço 26 - Coluna litológica e perfis geofísicos

Figure 2 - Well 26 -Lithological column and geophysical logs

A atuação de águas correntes na gênese dos sedimentos neste intervalo pode ser observada tanto macroscopicamente, pacote de 165,4 a $177 \mathrm{~m}$, quanto microscopicamente pelo estudo das seçoes delgadas no intervalo. Este intervalo deve representar, então, sedimentos gerados predominantemente por águas correntes em regime de fluxo inferior. Nos perfis geofisicos este intervalo caracteriza-se por apresentar arenitos eletricamente resistivos com emissão intensa de raios gama que são feições também identificadas nos poços 22 e 29.

INTERVALO IV (151 -138 M) - É constituído por diamictito arenoso, com arenito fino intercalado. O exame da seção 09, confeccionada em matriz do diamictito, evidenciou faixas bem individualizadas de porções arenosas, sílticas e argilosas. Nas faixas arenosas distinguem-se areias grossas e médias, com feldspatos potássicos e sedimentos finos e muito finos. O cimento é constituído de calcita $(82 \%)$, contendo intraclastos arenosos $(14 \%)$ e siltosos $(4 \%)$. As areias constituem-se de quartzo $(80 \%)$, feldspatos $(6 \%)$ e microclínio $(10 \%)$. O restante é constituído de minerais pesados (granada, zircão e, subordinadamente, hornblenda), além de mica. As areias são muito finas $(40 \%)$, finas $(23 \%)$ e médias $(8 \%)$. A faixa síltica é mal selecionada, constituída de silte $(70 \%)$, podendo-se distinguir silte muito fino (26\%), fino (32\%), médio (1 1\%) e grosso $(10 \%)$. As faixas argilosas formam pequenos níveis 


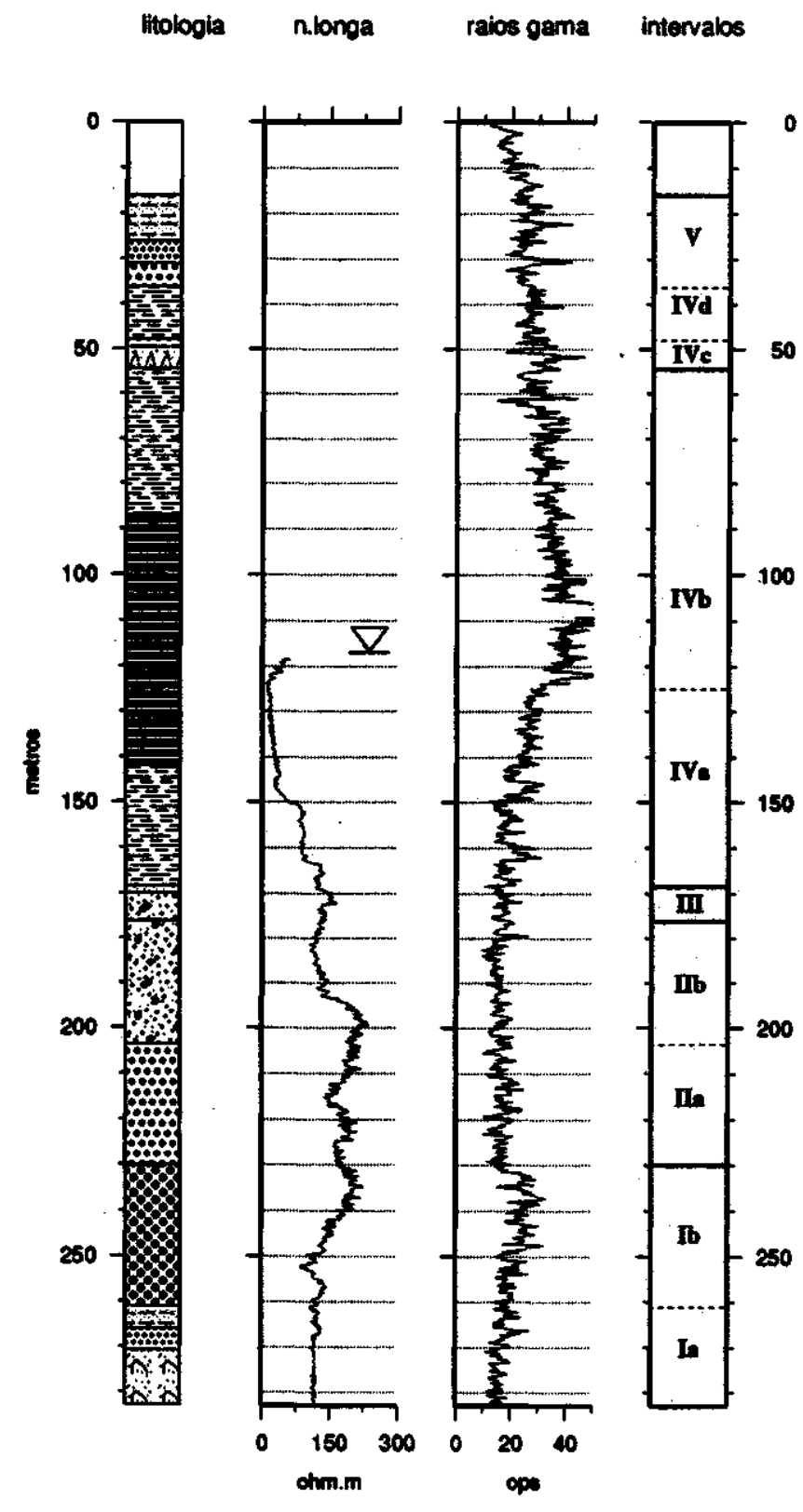

Figura 3 - Poço 29 - Coluna litológica e perfis geofisicos. Símbolos como na figura 2.

Figure 3 - Well 29 - Lithological column and geophysical logs. Symbols as in figure 2.

individualizados. As características microscópicas desta seção delgada são sugestivas de contribuição aquosa na deposição desta rocha.

A seção delgada 10 exibe matriz levemente estratificada, formando $15 \%$ da amostra, sendo que $10 \%$ écarbonáticae 5\% síltico-argilosa. Os clastos totalizam $75 \%$ sendo constituídos de quartzo $(50 \%)$, calcita (1\%), opacos $(4 \%)$, zircão (1\%), anatásio, rutilo e outros minerais titaníferos $(2 \%)$. Turmalina e mica aparecem como traços. A granularidade do sedimento é a seguinte: argila (2\%); silte (45\%) (muito fino, $3 \%$; fino, $9 \%$; médio, $9 \%$ e grosso $24 \%$ ); areia (53\%) (muito fina, $22 \%$; fina, $19 \%$; média, $9 \%$ e grossa, 3\%). Esta rocha é, portanto, um diamictito.

No perfil de resistividade normal longa este pacote caracteriza-se por valores excessivamente elevados, acima de 250 ohm.m, que devem expressar o efeito da cimentação carbonática que atinge até $10 \%$ do volume da amostra.

INTERVALO V(138- 6M) É caracterizado por uma sequência de granodecrescência ascendente que engloba os sub-invervalos $\mathrm{Va}(138-114 \mathrm{~m}), \mathrm{Vb}(1$ 14-97 m) e Vc (97-6 m). O intervalo Vá é constituído por arenitos finos, o intervalo $\mathrm{Vb}$ por ritmitos muito finos síltico-argilosos e o intervalo Vc por lamitos.

A granodecrescência ascendente é reconhecida nos perfis pelo aumento gradativo da emissão gama e diminuicão concomitante da resistividade. $\mathrm{O}$ limite entre os intervalos $\mathrm{Vb}$ e Vc, a $97 \mathrm{~m}$, caracteriza-se pelo aumento brusco na emissão de raios gama e, nos testemunhos, por delimitar pelitos com diferente estabilidade à decomposição, sendo os sotopostos mais estáveis por apresentar menor conteúdo em argila. Acima de $88,3 \mathrm{~m}$ não há medidas de resistividade elétrica, pois esta é a profundidade do nível estático.

Na descrição microscópica também é evidente a granodecrescência ascendente. A seção delgada 11 exibiu siltito rítmico com pequena quantidade de clastos sendo que $10 \%$ constitui-se de argila, $86 \%$ de silte (muito fino, $26 \%$; fino, $30 \%$; médio, $16 \%$ e grosso, $14 \%$ ) e $4 \%$ de areia (muito fina, $3 \%$ e fina, $1 \%$ ). A seção 12 , exibiu siltito rítmico ou ritmito fino, sendo que $15 \%$ constituiu-se de argila, $81 \%$ de silte (muito fino, 25\%; fino, 33\%; médio, $15 \%$ e grosso, $8 \%$ ) e $4 \%$ de areia muito fina. A secão 13, exibiu lamito com $48 \%$ de argila (filossilicatos, $70 \%$; clorita $10 \%$ e illita $10 \%$ ). Siltes comparecem com $40 \%$ (muito fino $17 \%$; fino $8 \%$; médio $6 \%$ e grosso $9 \%$ ) e areias com $12 \%$ (muito fina $6 \%$; fina $3 \%$; média $1 \%$; grossa $1 \%$ e muito grossa, $1 \%$ ). Os clastos da granulacão areia são constituídos por quartzo (70\%), plagioclásios $(10 \%)$, microclínio $(18 \%)$ e mica, calcita e mais minerais pesados $(2 \%)$ (opacos, granada, anatásio, turmalina, zircão, hornblenda e apatita).

Poço 29 Neste poço foram reconhecidos cinco intervalos de sedimentos, mostrados na figura 3 .

INTERVALO I (283-230M) É formado pelos sub-intervalos Ia e Ib. No sub-intervalo Ia, de 283 a $261 \mathrm{~m}$, predominam arenitos conglomeráticos com matriz e com seixos e calhaus de diversas litologias. Subordinadamente, ocorrem conglomerados sustentados pela matriz. No sub-intervalo $\mathrm{Ib}$, de 261 a $230 \mathrm{~m}$, ocorrem arenitos grossos e conglomerados, com seixos esporádicos de quartzito.

Nos perfis, valores entre 25 e $30 \mathrm{cps}$ indicam que é significativa a presença de finos no pacote; os valores elevados de resistividade podem ser causados pelos clastos de quartzito e granito e pela cimentação carbonática identificadas no testemunho.

INTERVALO II (230-176,1 M) É formado por dois sub-intervalos. O sub-intervalo lia, de 250 a 203,5 m é formado por arenitos médios com cimento calcífero e intercalações irregulares de argilito dispostos subhorizontalmente. Nos perfis geofísicos o intervalo Ila caracteriza-se por baixa emissão de raios gama, na faixa de 15 a $20 \mathrm{cps}$, e resistividade $185 \mathrm{ohm} . \mathrm{m}$ em média. O sub-intervalo Ilb, de 203,5 a 176,1 m constituise de arenitos médios e arenitos grossos com muita matriz que leva a resistividade cair para $110 \mathrm{ohm} . \mathrm{m}$.

INTERVALO III (176,1-168,3 M) Inicia-se com brecha constituída por extraclastos e intraclastos de argilito escuro em matriz arenosa $(176,1-175,9)$, seguindo-se arenitos grossos e médios intercalados, sub-horizontais ou ligeiramente inclinados. Subordinadamente ocorrem arenitos conglomeráticos e lâminas de argilito. No topo, ocorrem arenitos finos 
(170-168,3 m). Destaca-se a boa separação granulométrica dos termos litológicos, embora existam contatos irregulares em alguns casos. Esta característica, associada a laminações cruzadas não tangenciais e laminações cruzadas cavalgantes de pequeno porte, presentes em certos níveis, são sugestivas de ação de água corrente como geradora dos sedimentos deste intervalo.

INTERVALO IV (168,3-54,4 M) É constituído por quatro sub-intervalos que registram o afogamento da bacia pelo mar Capivari, que gerou os sedimentos mais facilmente correlacionáveis em todos os poços.

O sub-intervalo IVa, de 168,3 a 125 m, mostra uma sequência de granodecrescência ascendente associada com o aumento na emissão gama e concomitante decréscimo na resistividade elétrica. Litologicamente é constituído por arenitos sílticos e siltitos, com estrutura rítmica ou formando corpos isolados. Subordinadamente, no topo do sub-intervalo, ocorrem níveis conglomeráticos, lamíticos e com cimentação carbonática. Alguns contatos são irregulares e subverticais sugerindo deslizes subaquáticos.

O sub-intervalo, IVb, de 125 a $54 \mathrm{~m}$, registra a etapa final do afogamento. E constituído por siltitos e argilitos com emissão gama maior que $35 \mathrm{cps}$. $\mathrm{O}$ incremento abrupto na emissão gama entre 124 e $108 \mathrm{~m}$, deve indicar a fase de maior afogamento. A variação entre 108 e 47,9 m pode refletir uma flutuação do nível relativo do mar.

O sub-intervalo IVc, de 54,4 a 47,9 m, foi definido a partir da descrição dos testemunhos que identificou arenitos conglomeráticos, mal selecionados com extraclastos de litologias diversas, formas angulosas e facetadas e dimensões na fração de seixos e calhaus. Descreve-se um fragmento de quartzito com diâmetro de 25 centím . Litologicamente, este sub-intervalo é um diamictito arenoso, com passagens irregulares para arenitos médios e finos, intercalados com arenito grosso.

O sub-intervalo IVd, de 47,9 a 36,2 m, é constituído de siltito maciço, homogéneo semelhante àqueles no sub-intervalo IVb. O sub-intervalo IVc pode, então, ser interpretado como formado por um deslize sindeposicional associado com um abaixamento esporádico do nível relativo do mar.

INTERVALO $V(36,2-15,9 M)$ É constituído, da base para o topo, por arenitos médio, fino e muito fino, exibindo nítida granodecrescência ascendente.

Poço 22 Neste poço, reconheceram-se cinco intervalos de sedimentos (Fig. 4).

INTERVALO I (300-243 M) No sub-intervalo Ia, de 300 a $282,8 \mathrm{~m}$, ocorrem sucessões de brechas e conglomerados sustentados pela matriz, com intraclastos argilo-carbonosos com estratificação irregular. Entre estes ruditos ocorrem arenitos finos, muito finos, médios e grossos. Lâminas de argilito, às vezes carbonosos, são subordinados. Verificam-se estruturas de sobrecarga ("flames") causadas por arenito médio sobre fino. De 282,8 a 282,2 m, ocorre arenito predominantemente fino com intercalações de grosso com extra e intraclastos e fragmentos tabulares de argilito carbonoso.

A seção delgada 14, na base do poço, exibiu sedimentos com baixíssima seleção constituídos de areias médias, grossas e muito grossas, contendo grânulos, cimento poiquilotópico de calcita e pouca matriz sericítica. Os clastos são compostos de quartzo $(60 \%)$, plagioclásios $(10 \%)$, microclínio $(17 \%)$ e rocha fina (gnaisse, siltito, diabásio, cloritaxisto e granito).

O sub-intervalo Ib, de 282,8 a 243 m, mostra uma sucessão de arenitos finos com muita matriz e intercalações de lâminas argilosas, e pequenos fragmentos de carvão. Ocorrem também arenitos médios com fragmentos tabulares de argilito carbonoso.

As seções delgadas 15 e 16 são compatíveis com as descrições macroscópicas. A primeira, exibe areia fina a média, com pouca seleção, baixo arredondamento e pouca matriz

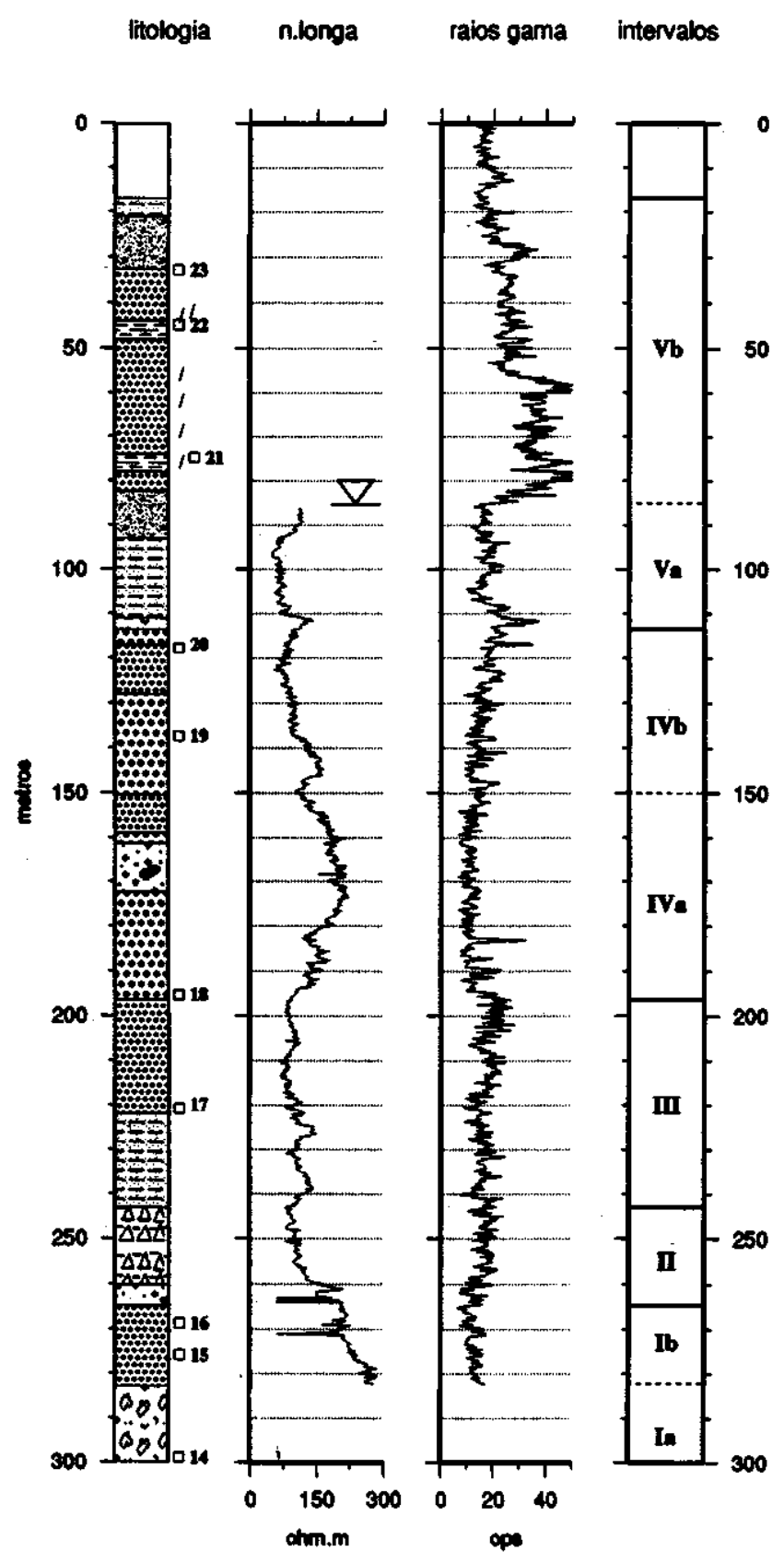

Figura 4 - Poço 22 - Coluna litológica e perfis geofisicos. Simbolos como na figura 2.

Figure 4 - Well 22 - Lithological column and geophysical logs. Symbols as in figure 2.

síltico-argilosa (sericítica). Os clastos compõem-se de quartzo $(70 \%)$, plagioclásios $(10 \%)$ e microclínio $(20 \%)$. Aparecem como traços, uma rocha fina, micas, cloríta e minerais pesados (turmalina, zircão e outros). A seção delgada 16, exibe areia média, com boa seleção e arredondamento e cimento poiquilotópico calcítico, pouca sericita na matriz, rara e como alteração de feldspato. Os clastos são compostos por quartzo $(70 \%)$; plagioclásios $(10 \%)$; microclínio $(15 \%)$ e uma rocha fina $(5 \%)$. 
Nos perfis geofísicos os arenitos deste intervalo caracterizam-se pela baixa emissão de raios gama, entre 15 e $17 \mathrm{cps}$, e resistividade elétrica crescente com a profundidade, chegando a valores maiores que 250 ohm.m a $284 \mathrm{~m}$, que certamente expressam a diminuição de porosidade causada pela cimentação carbonática. Coincidência ou não nota-se outra vez a ocorrência de arenitos muito resistivos no topo de uma sequência arenosa.

A energia do meio líquido onde se processou a sedimentação deve ter decrescido rumo ao topo até atingir uma condição de regime de fluxo inferior.

INTERVALO II (264,7-243 M) Este intervalo inicia-se com um arenito conglomerático que afina, em granodecrescência ascendente, até arenito fino a médio, de 264 a $263 \mathrm{~m}$. O contato basal do arenito conglomerático, a $264,7 \mathrm{~m}$, ocorre sob a forma de diastema com o arenito muito fino inferior.

De 263 a 260,2 m, ocorrem intercalações de arenito grosso, médio e fino, com contatos sub-horizontais, passando para subverticais a partir de $260,3 \mathrm{~m}$, sendo alguns estratos interrompidos lateralmente.

De 260,2 a $243 \mathrm{~m}$, ocorre um diamictito maciço de matriz lamítica, com clastos angulosos ou subarredondados de granito e quartzito, de até 25 centím de diâmetro mínimo, geralmente sem evidências de intemperismo e intraclastos de arenito fino.

O nível de energia no meio líquido deve ter sido elevado, maior que aquele que se estabeleceu no intervalo sotoposto.

INTERVALO III (243-196,5 M) Constitui-se, basicamente, de arenitos finos. Da base até $223,8 \mathrm{~m}$, ocorrem arenitos muito finos com lâminas argilosas sub-horizontais e localmente inclinadas, distribuídas irregularmente com relativa frequência.

Entre 223,8 e 221,7 m, comparecem arenitos médios, maciços, sem lâminas argilosas. $\mathrm{O}$ trecho superior é constituído de arenito fino e, subordinadamente, arenito médio com lâminas argilosas intercaladas.

A seção delgada 17 indica areias finas com matriz sericítica rara. Os clastos constituem-se de quartzo $(75 \%)$, plagioclásios $(10 \%)$; microclínio $(12 \%)$ e rocha fina $(3 \%)$. Como traços, aparecem micas e minerais pesados (turmalina, zircão, rutilo e opacos). Os sedimentos deste intervalo distinguem-se do inferior, onde predominam ruditos, por serem formados em condições aquosas de energia moderada.

É importante ressaltar que os perfis geofísicos não acusaram claramente as variacões litológicas entre o intervalo II (diamictitos) e a base do intervalo III (arenitos muito finos com intercalações argilosas). Por possuir matriz argilosa, a resposta do diamictito torna-se semelhante à do arenito pois ambos possuem conteúdo em argila na mesma ordem. Neste caso, o diamictito pode facilmente ser confundido com um lamito induzindo erros grosseiros quando se infere o ambiente de sedimentação do intervalo.

INTERVALO IV (196,5-113,6 M) É composto por dois sub-intervalos sendo o contato com o intervalo III, do tipo diastema. O sub-intervalo IVa, de 196,5 a $150 \mathrm{~m}$ é constituído por arenitos médios, com raras intercalações argilosas e, subordinadamente, por arenitos grossos. Compativelmente com a descrição litológica, os perfis apresentaram os menores valores de emissão de raios gama, inferiores a $15 \mathrm{cps}$, e resistividade de $180 \mathrm{ohm} . \mathrm{m}$ frente a estes arenitos. $\mathrm{O}$ aumento na emissão de raios gama e diminuição na resistividade no intervalo de 159 a 150 m sugerem uma sequência de granodecrescência ascendente, que foi verificada nos testemunhos: na base a litologia predominante é de arenitos muito finos a médios aumentando a frequência de lâminas argilosas rumo ao topo.

Microscopicamente, a seção delgada 18 , pouco acima de um diastema, exibe granulação de areia média, grossa e muito grossa, com má seleção e bom arredondamento. A associação de má seleção com bom arredondamento pode significar retrabalhamento de sedimentos prévios. Nesta seção verificou-se a seguinte composição de clastos: quartzo (72\%); plagioclásios $(10 \%)$; microclínio $(15 \%)$ e rocha fina $(3 \%)$. A participação de mica e sericita, originadas na alteração dos feldspatos, é pouco representativa na matriz.

O sub-intervalo IVb, de 150 a $113,6 \mathrm{~m}$, embora também constituído de arenitos, destaca-se pelo aumento de emissão de raios gama rumo ao topo. Este aumento não está relacionado com o aumento na argilosidade pois a análise dos testemunhos não caracterizou a granodecrescência ascendente. É oportuno notar que horizontes arenosos semelhantes ocorrem no poço 26, intervalo $\mathrm{Vc}$, devendo pois estarem correlacionados.

A seção delgada 19 exibiu areia fina a média, com raros grãos grossos e lentes de silte grosso, cimento calcítico poiquilotópico. A matriz é elástica com menos que $5 \%$ de silte fino a muito fino e sericita. $\mathrm{O}$ clastos são constituídos por quartzo $(70 \%)$; plagioclásios $(15 \%)$; microclínio $(10 \%)$; rocha fina $(3 \%)$; pesados ( $2 \%$ ) (granada, opacos, zircão e turmalina).

A seção delgada 20 revelou areia média, bem arredondada e com boa seleção, intercalada com um sedimento de baixíssima seleção, variando de areia muito fina a média. Composição dos clastos: quartzo (70-80\%); feldspatos (plagioclásios mais microclínio) (20-30\%).

Infere-se que neste intervalo, a sedimentação ocorreu em meio aquoso com energia alta a ponto de impedir a deposição de pelitos em quantidade apreciável.

INTERVALO V (113,6-17 M) Compõe-se por dois subintervalos. O Vá, de 113,6 a $85 \mathrm{~m}$, apresenta entre 113,6 a 111 $\mathrm{m}$, um conglomerado com matriz arenosa, clastos subarredondados de tamanhos variados, desde 7 centím de diâmetro mínimo até a granulação de seixos. $\mathrm{O}$ trecho restante é constituído de arenitos grossos, médios, finos e muito finos, passando a siltito acima. Laminações verticais desenvolvem-se de 104 a $101,6 \mathrm{~m}$.

No sub-intervalo $\mathrm{Vb}$, de 85 a $17 \mathrm{~m}$, as emissões de raios gama aumentam bruscamente, principalmente entre 85 a 58 $\mathrm{m}$, sugerindo o aumento no conteúdo em finos embora macroscopicamente tais litologias tenham inicialmente sido descritas como arenitos finos. As seções delgadas 21 e 22, entretanto, exibiram silte grosso e areia fina corroborando com a interpretação dos perfis e caracterizando este pacote como arenito síltico.

As descrições pormenorizadas das seções são dadas a seguir. A seção 22 mostra um silte médio a grosso, bem selecionado, com matriz sericítica. Composição dos clastos: quartzo (65\%); plagioclásio (2\%); microclínio $(20 \%)$; micas (1\%); calcita e minerais pesados (opacos, zircão, granada, rutilo e turmalina), traços. A matriz sericítica forma $10 \%$ da amostra. Na seção delgada 23 foram verificadas duas bandas: uma com areia fina a média, arredondamento relativamente bom, matriz síltica fina e o cimento calcítico; outra constituída de areias finas passando para muito finas, silte grosso até argila. A quantidade de clastos na primeira banda é: quartzo $(60 \%)$, plagioclásios $(15 \%)$, microclínio $(20 \%)$, rocha fina $(5 \%)$, micas e traços de minerais pesados (turmalina, granada, apatita e opacos). Na outra banda: quartzo (65\%); plagioclásios $(15 \%)$; microclício $(15 \%)$; rocha fina $(5 \%)$; micas e traços de minerais pesados (turmalina, granada, apatita e opacos).

Um aspecto marcante do sub-intervalo $\mathrm{Vb}$ é a quantidade de estruturas rúpteis identificadas nos testemunhos. Nota-se laminações, com predomínio de arenito muito fino e subordinadamente arenito fino, em contatos subverticais e o desenvolvimento de superficies espelhadas associadas com falhas normais. De 57,8 a 53,5 m, predominam arenitos finos intercalados com muito finos, dispostos caoticamente e, a partir de 
57 m, as lâminas dispõem-se subverticalmente. Ocorrem, também, emaranhados irregulares de siltito envolvendo arenito muito fino.

Em 52 m, uma falha normal atravessa o testemunho, com espelho de falha e estrias. Contatos subverticais com laminações deslocadas por pequenas falhas voltam a aparecer de 48 a $45 \mathrm{~m}$. De 45 a $44 \mathrm{~m}$, verificam-se misturas caóticas de arenitos de diversas granulometrias, atribuídas a liqüefacãa. Estruturas subverticais também desenvolvem-se de 43 a 42,5 $\mathrm{m}$. A $41 \mathrm{~m}$, arenitos finos e muito finos alternam-se em estrutura rítmica, dispondo-se em grandes ondulações em forma de sela. A 40,4 m, a laminação está muito fragmentada, em forma de blocos. De 37 a $36,5 \mathrm{~m}$, ocorrem arenitos finos com lâminas sílticas em disposição irregular e de 36,5 a 32,5 $\mathrm{m}$, voltam a aparecer laminacões subverticais com as mesmas litologias. De 31 a 30,5 m, ocorrem arenitos finos, laminados, intercalacões de siltito cortados por pequenas falhas. Arenito muito fino em contato subvertical com arenito fino aparecem de $30,5 \mathrm{a} 28,8 \mathrm{~m}$.

O nível de energia neste intervalo deve ter sido baixo, menor que o do intervalo anterior.

Correlação Entre os Poços A figura 5 mostra a correlação estratigráfica inferida para os sedimentos da região com base no estudo integrado. Reconheceram-se quatro pacotes litológicos principais, denominados A, B, C e D.

PA COTE D O pacote D é constituído por litologias psefíticas e psamíticas, tendo sido alcançado apenas no poço 22 . E constituído por brechas e conglomerados suportados pela matriz e arenitos com grânulos, muito grossos, grossos e médios. Um diastema o separa do pacote $\mathrm{C}$.

PACOTE C Este pacote, apesar de englobar diversas litologias, caracteriza-se por apresentar maior conteúdo em finos que as demais sequências. Os finos aparecem formando lamitos, siltitos e ritmitos, como também constituindo lâminas no interior de arenitos finos e médios e na matriz dos diamictitos. A energia do meio aquoso deve ter sido baixa em alguns horizontes, chegando mesmo a formar lamitos com preservação da matéria orgânica (Intervalo I do poço 26) e elevada em outros, resultando fluxos de detritos que retrabalharam os finos pré-existentes, formando diamictitos sustentados pela matriz ( Intervalo II do poço 22) ou arenitos com lâminas argilosas.

O maior conteúdo em finos aumenta a contagem gama frente a este pacote, tornando-o reconhecido em todos os poços. Verifica-se a predominância de sedimentos mais finos no poço 26 em relaçẫo aos outros poços, sugerindo, do ponto de vista paleogeográfico, porções mais rasas rumo nordeste e, portanto, um continente emerso nesta direção ( vide Fig. 1). Esta sugestão é coerente com os resultados de mapeamentos geológicos do município de Rafard, os quais não identificaram arenitos de granulação maior que a média ( Santoro et al, 1994).

O contato do pacote $\mathrm{C}$ com o $\mathrm{B}$ é do tipo erosivo. No poço 26 , intervalo II, ocorre uma brecha.

PACOTE B É constituído por sedimentos, predominantemente arenosos, com duas características distintas. Na base, predominam arenitos mais grossos, com facies sedimentares condicionadas pela variação de argila e, no topo, arenitos com maior emissão de raios gama, particularmente intensa nos poços 26 e 22. Tais arenitos devem ter sido depositados sob a ação de aguas correntes com energia moderada, com pouca ou nenhuma fase de turbilhonamento e com a energia diminuindo rumo ao topo. A cimentação carbonática, identificada em seções delgadas nos poços 22 e 26 e pelo aumento da resistividade elétrica nos três poços, tende a se concentrar no topo do pacote.

O contato do pacote $\mathrm{B}$ com o pacote A é do tipo erosivo, reconhecendo-se nos três poços, um horizonte de elásticos grossos: diamictito no topo do intervalo IV do poço 22 , brecha sedimentar no interrvalo III do poço 29 e horizonte conglomerático no intervalo IV do poço 26.

PACOTE A Registra-se aqui um episódio de afogamento da bacia pela subida do nível do mar Capivari. $O$ afogamento imprimiu marcante granodecrescência ascendente nos três poços. A presença de ilita entre os argilominerais reforça o argumento de sedimentação marinha. Nos perfis geofísicos a granodecrescência ascendente imprimiu aumento gradativo na emissão de raios gama e diminuição concomitante da resistividade elétrica rumo ao topo do pacote. Conforme sugerem os perfis geofísicos e verificado pela análise dos testemunhos, a variação de facies sedimentar está associada com o aumento, para cima, do conteúdo de argila.

No poco 26 o pacote é constituído basicamente por lamitos, enquanto nos poços 22 e 29 descrevem-se arenitos muito finos e arenitos sílticos. Esta mudanca na granulometria no pacote sugere variação lateral de facies e corresponderia, do ponto de vista paleogeográfico, a posições mais rasas na encosta de uma rampa submarina rumo nordeste já configurada durante a deposição do pacote $\mathrm{C}$, como mencionado acima.

O reconhecimento de níveis estratigráficos dentro da sequência permite correlacionar litologias bastante diversas. As falhas e estruturas de liqüefação no sub-intervalo $\mathrm{Vb}$ do poço 22, os níveis conglomeráticos no topo do subintervalo IVa no poço 29 e a diminuição de contagem gama no subintervalo Vc do poço 26, por exemplo, parecem expressar um mesmo episódio na sequência deposicional, ou seja, diminuição do nível relativo do mar apos o afogamento da bacia. Na parte distai, isto é, no poço 26, este evento se expressaria pela diminuição de raios gama e, no poço 22, por instabilidade nos sedimentos preformados que, eventualmente sofreriam colapso que gerariam fluxos de detritos, tal como se observa no topo do subintervalo IVa do poço 29. Esta situação compartimentaliza, dentro do pacote $\mathrm{A}$, as estruturas rapteis identificadas no poço 22 .

IMPLICACÕES HIDROGEOLÓGICAS A correlação apresentada na figura 5 mostra que os arenitos dos pacotes $\mathrm{B}$ e D constituem os dois principais aquíferos da região; o primeiro sendo cortado por todos os poços e o segundo apenas pelo poço 22 em Capivari. O nível estático dos poços coincide com o horizonte de maior emissão gama dentro do pacote $\mathrm{A}$, indicando que este nível pode estar condicionado pela litplogia. $\mathrm{O}$ aquífero $\mathrm{B}$ é confinado pelo pacote A na região de Rafard, porém semi-confinado em Capivari onde os sedimentos deste pacote gradam para arenitos sílticos, sem alcançar, entretanto, as facies pelíticas que se observam em Rafard (especialmente no poço 26). A zona de recarga deste aquífero deve situar-se um pouco mais a nordeste de Capivari onde afloram os sedimentos mais grossos. Cabe ressaltar que a intensificação do bombeamento na zona de recarga, ou próximo a ela, pode eventualmente diminuir as vazões nos poços de Rafard que cortam apenas a parte confinada do mesmo. Já o aquífero D é confinado em toda a região e deve ser interceptado na região de Rafard em profundidades maiores que $300 \mathrm{~m}$.

\section{INTEGRAÇÃO COM POÇOS ANTERIORES Os}

perfis de correlacão propostos para os três pocos (Figura 5) estão sendo distribuídos de acordo com seus afastamentos da antiga borda do mar Capivari. Verifica-se, nestes perfis, a importância da contribuição de sedimentos depositados em condições de baixa energia nos poços mais distais. 


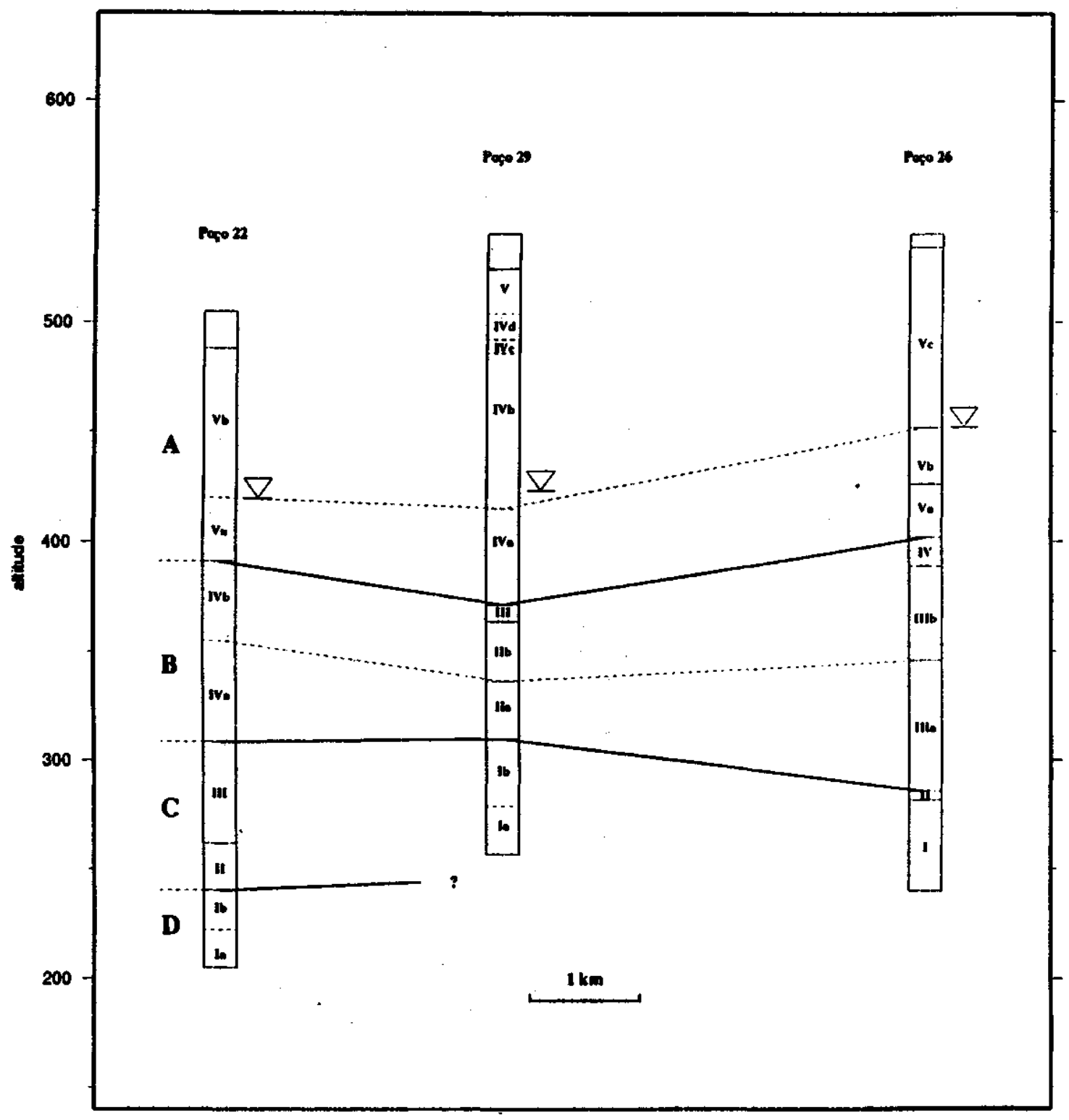

Figura 5 - Correlação dos poços. O pacote D, presente só no poço 22, é constituído por brechas e conglomerados suportados pela matriz, e arenitos com grânulos, muito grossos, grossos e médios, mal selecionados. Um diastema separa os intervalos $D$ e $C$. $O$ intervalo $C$ se inicia por granodecrescência ascendente. Menores valores no perfil de raios gama e falta de especularídade entre as curvas de raios gama e de resistividade, distinguem o intervalo $B$ do $C$. O último intervalo A, é caracterizado, em todos os poços, por granodecrescência ascendente, evidenciando o afogamento do " mar Capivari "

Figure S - Correlation of the wells. Interval D, present only in the well 22, is made up of breccias and matrix-supported conglomerates, and very coarse, coarse and médium poorly sorted sandstones with granules. A diastem is located between D and C. Fining upward from the basis characterizes interval C. A shift toward lower gamma-rays counts as well as a lack of specularity between the garnma and resistivity logs distinguish interval B and $\mathrm{C}$. The fiming-upward succession in the geológica! columns of the three wells characterizes the uppermost interval

O poço Capim Fino, perfurado pelo IG-SMA antes de 1985, descrito por Maniakas (1986), dista pouco menos de 2 quilôm a sudoeste do poço 3 (Petri, 1992). Coerentemente com o que ocorre em outros poços de Rafard, aqui também é grande a espessura de sedimentos de granulação fina. $\mathrm{O}$ poço 13, com profundidade de $101 \mathrm{~m}$, é uma exceção na área de Capivari pois apresentou sedimentos predominantemente finos (49 m contínuos no topo do poço) o que pode ser indício de um remanso local não atingido pelos fluxos de detritos. Durante a deposição, os níveis contemporâneos nos poços deviam mergulhar rumo ao poço mais afastado da borda marinha, ou seja, na seguinte ordem: 22, 29, 3 e 26.
CONCLUSÕ ES Verifica-se, como regra, que pelitos são mais frequentes nas partes superiores dos poços aumentando em quantidade rumo ao município de Rafard enquanto os poços de Capivari são predominantemente psamíticos. Tal variação granulométrica é compatível com a existência de um continente emerso a NE com a sedimentação procedendo-se rumo SW. Este contexto paleogeográfico deve ter persistido durante toda a deposição dos pacotes sendo entretanto mais evidente nos pacotes $\mathrm{A}$ e $\mathrm{C}$ que representam está gios de maior afogamento da bacia.

A profundidade das interfaces entre os pacotes sedimentares não apresentam variações bruscas sugerindo que os sedimentos não foram afetados por falhamentos tectônicos 
34

apreciáveis. As estruturas rúpteis identificadas no poço 22 ocorrem apenas internamente ao pacote de sedimentos da sequência mais superficial não se estendendo em profundidade, podendo ser atectônicas.

Finalizando, cabe ressaltar a importância do estudo integrado, envolvendo descricão de testemunhos, estudos em seção delgada e perfis geofísicos para efetuar-se a correlação entre os poços.
Agradecimentos Os autores agradecem ao IG-SMA pelo apoio recebido e pela permissão de divulgar os resultados obtidos e à doutoranda Teresa Yamabe pela revisão do artigo. $\mathrm{O}$ perfilador empregado foi adquirido pelo Departamento de Geofisica do IAG-USP no PADCT-87. O segundo co-autor recebeu apoio do CNPq, Processo 301439/91-5, durante a realização deste trabalho.

\section{REFERÊNCIAS}

MANIAKASS. 1986. Estudos Geofisicos Integrados à Geologia da Bacia Hidrográfica do Baixo Capivari-SP (Subgrupo Itarare e Intrusivas Associadas). São Paulo. 180 p. (Tese de Doutoramento, Instituto de Geociências da Universidade de São Paulo)

PAULA NETO, F.J.S. 1988. Variação da Eletrorresistividade como Teor de Óleo dos Folhelhos da Formação Irati. São Paulo. 32 p.(Trabalho de Graduação 2, Instituto Astronómico e Geofísico da Universidade de São Paulo)

PETRI, S. 1992. Litpfacies e Significado Paleoambiental dos Sedimentos Itararé na Região Capivari-Rafard, Estado de São Paulo. Revista do Instituto Geológico, IG-SMA,SP,13(1):7-30.

PETRI, S. \& PIRES, F.A. 1992. O Subgrupo Itararé (Permocarbonífero) na Região do Médio Tietê, Estado de São Paulo. Revista Brasileira de Geociências, SBG, São Paulo, 22(3): 301-310.

PIRES, F.A. \& PETRI S. 1991. O Subgrupo Itararé na Região Capivari-Rafard, Estado de São Paulo. In: SIMPÓSIO REGIONAL DE. GEOLOGIA DO. SUDESTE, 2, São Paulo, Atas, São Paulo, SBG, Núcleos SP e RJ/ES, p. 391-396.
RIDER, M.H. 1990. Gamma-ray log shape used as a facies indicator: critical analysis of an oversimplified methodology. In: HURST, A., LOVELL, M. A., \& MORTON, A. C. (eds), Geological applications of wireline logs, Geological Society Special Publication No. 48, p. 27-37.

SANTOROJ, ODA, G.H. MASSOLI, M. PETRI, S, AZEVEDO, A.A.B TOMINAGA, L.K. \& BOTELHO, P.F. 1994. Contribuicão à hidrogeologia do município de Rafard, SP in CONGR.BRAS. GEOL.,Camboriu, SC, Boi. Resumos Exp, SBG, p. 332-333..

TELFORD, W..M., GELDART.L.P.. SHEREFF.R.E., KEYS, D.A. 1976. Applied Geophysics. Cambridge University Press. 860 p.

Manuscrito A84'

Recebido em 12 de junho de 199)

Revisão do autor em 20 de setembro de 199i Revisã 0 aceita em 23 de setembro de 199i 